\title{
Research on the Implementation of Flipped Classroom in the World Economy Course
}

\author{
Chenggang Wang* \\ School of Economics and Business Management, Heilongjiang University, Harbin 150080, China \\ *Corresponding author: Chenggang Wang, wangchenggang@hlju.edu.cn
}

\begin{abstract}
In the context by which the World Economy course is restricted by the traditional teaching model, the flipped classroom model can solve the issues in the teaching process. The flipped classroom can systematically strengthen teacherstudent interaction during and after classes, optimize students' learning habits, improve students' learning effect, and effectively provide timely feedback on the teaching effect. Therefore, the World Economy course should implement flipped classrooms and put forward corresponding safeguard measures, including actively changing the role of teachers, effectively guiding students to participate in flipped classrooms, equipped with sufficient and high-quality software and hardware equipment, as well as promoting the scientific evaluation of flipped classroom teaching effect.
\end{abstract}

Keywords: Flipped classroom; World Economy course; Teaching process

Publication date: November 2021; Online publication: November 30, 2021

\section{Introduction}

In recent years, with the rapid progress of science and information technology, massive internet teaching resources and efficient communication methods have promoted the development of various new educational methods in modern educational practice and related teaching research ${ }^{[1-3]}$. Among them, the teaching method of flipped classroom has attracted people's attention. Judging from the research results of previous scholars, "flipped classroom" is mainly to change the traditional "cracking duck education," transfer knowledge outside the classroom, allow students to complete their work independently, and share the internalized knowledge within the classroom. The core connotation of flipped classroom is mainly based on modern informatization hardware and software environment. Learners can use various informatization methods to realize the basic knowledge of autonomous learning before classes and the systemic internalization of knowledge through various tasks in classrooms. After classes, it is necessary to complete the homework given and provide feedback on the learning effect. This new education model can eliminate the drawbacks of traditional education to a greater extent and improve the efficiency of education.

\section{Implementation of flipped classroom in the World Economy course}

Based on the results of practical research and combining the basic characteristics of the flexibility and interactivity of the flipped classroom and the current situation of course teaching, this article summarizes the specific implementation process of the flipped classroom model in the World Economy course. The details are shown in Figure 1.

\subsection{Interaction before class (online)}

Before classes, teachers can use relevant software to put up tasks for students online, such as to preview 
contents from textbooks or PowerPoint (PPT) courseware, to read current news affairs, to search for related current news affairs, cases, or classroom knowledge contents for the upcoming class, to watch or listen to videos or audios shared in advance, and to read up on certain topics which would be discussed in the upcoming class, in order to prepare their discussion contents. Students should pay attention to the contents uploaded by the teacher in a timely manner, take note of these pre-study tasks, and fully prepare for the upcoming class. In the preparatory process, students may not be able to fully understand certain points; hence, students should be encouraged to bring up the issues faced during preparation while having lessons in order to solve them ${ }^{[4,5]}$.

In terms of hardware usage, both teachers and students can use computers or smartphones to operate. In terms of software usage, there are many software options available for teachers and students on the market, and most of them are free to use, such as learning software, today's campus software, cloud class software, etc. Through the use of both hardware and software, teachers and students would be able to communicate better.

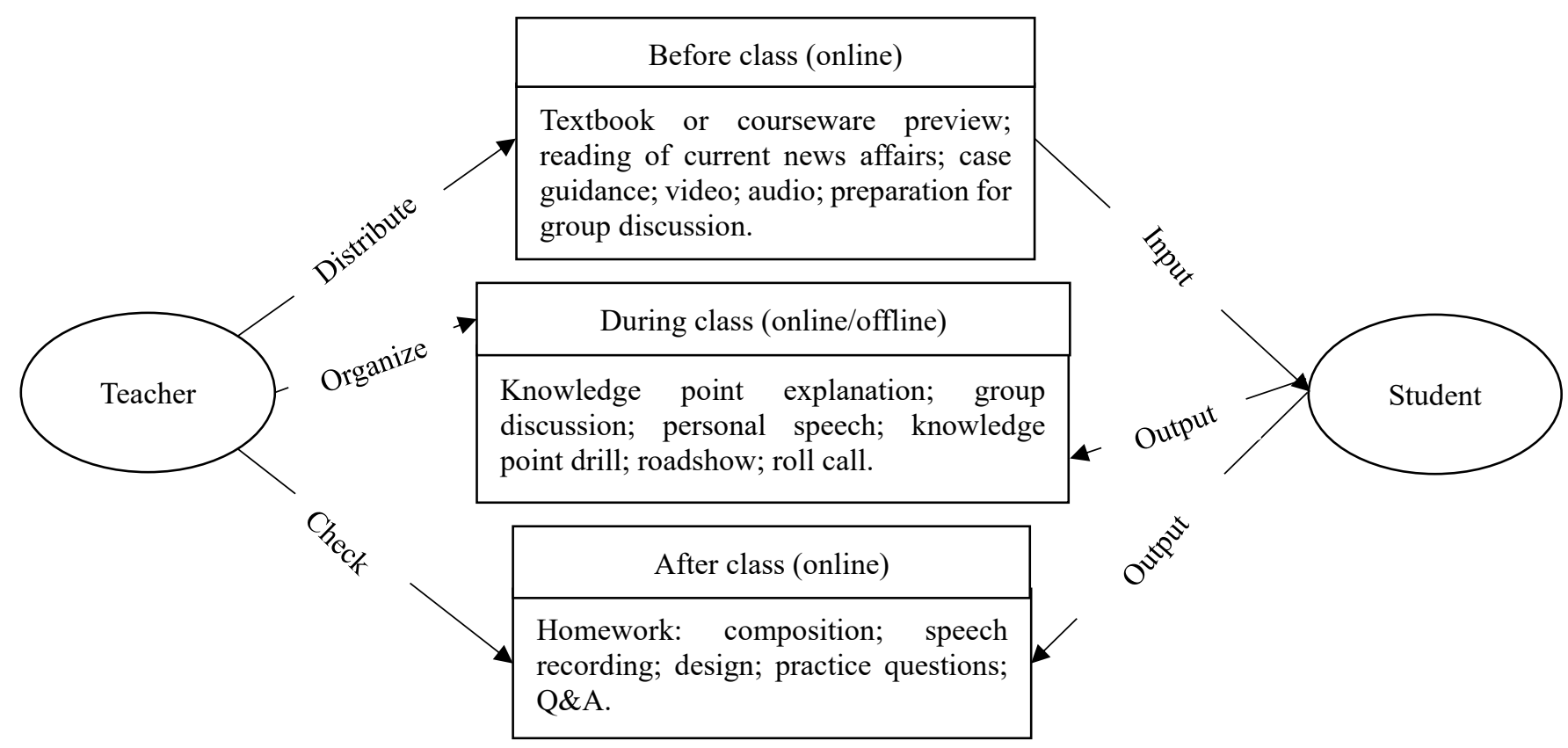

Figure 1. Teaching process of flipped classroom in the World Economy course

\subsection{Interaction during class (online and offline)}

In classrooms, teachers can use a combination of online and offline methods. For example, roll call and grouping can be done via online software. Within the first 10 minutes, the key knowledge points for each lesson can be explained. Subsequently, group discussions, speeches, knowledge point exercises, roadshows, etc. can be carried out. In this process, teachers mainly play the roles of organizers and supervisors, rather than protagonists; the real protagonist in classrooms should be the students. Only when there is a question or an error during discussion, the teacher should evaluate or put forward key guidance, so as to ensure the entire lesson goes smoothly ${ }^{[6]}$. At the same time, students should actively share the contents that they have prepared before classes and further generate ideas to share their opinions during lessons. In that way, there would be a collision of ideas, thus strengthening their understanding of relevant knowledge points. With research and analysis on cases, their practical application of theoretical knowledge can also be improved. 


\subsection{After class (online) interaction}

After classes, the interaction between teachers and students is largely online based. Teachers should post the homework for students in a timely manner after lessons. Homework here can be in the form of essays, questions, speech recordings, etc. In view of different course contents, teachers can choose different forms of online submission for students' homework. In terms of setting the time for homework submission, teachers can flexibly designate a time for homework submission in line with their students' learning progress and status, so as to ensure that the students have sufficient time to complete them. In addition, whenever students have any questions about the course content after lessons, they can communicate with their teachers online. In that way, they would be able to receive a quick reply. Teachers should emphasize on students' after-school question and answer (Q\&A) session. Other than that, they should also summarize the teaching effects of the course through online communication after each lesson, continue to reflect, and actively seek out the deficiencies in their own teaching, so as to improve the their teaching skills for future purposes.

\section{Guarantee measures for the implementation of flipped classroom in the World Economy course}

\subsection{Actively transforming the role of teachers}

The transformation of the role of teachers in the World Economy course requires a process. This process requires teachers to actively improve their ideological awareness, take the initiative to recognize the contributing role of flipped classrooms, and actively cooperate with various measures of flipped classrooms to achieve rapid adaptation to the role. Especially in the pre- and post-class stage, teachers need to make more effort than before. This is the task that must be completed in the process of transformation. At the same time, the transformation of the role of teachers in flipped classrooms also requires active guidance from schools and colleges; for example, by organizing training and issuing policy documents. Schools must also recognize this change in the role of teachers. In the daily process of teaching evaluation and assessment, the teaching achievements of teachers who participated in flipped classrooms should be affirmed. Especially in terms of workload assessment and job performance, schools should provide encouragement in terms of financial means to teachers who are actively participating in flipped classrooms. The implementation of the above measures would inevitably promote the transformation of the role of teachers to a certain extent and would be conducive to the smooth development of the flipped classroom model in the World Economy course.

\subsection{Effectively guiding students to actively participate in flipped classrooms}

First of all, during enrollment, relevant managers should clearly introduce the actual purpose and important role of flipped classrooms to freshmen. Schools do not only use the flipped classroom model in the World Economy course, but also throughout the school. Through this kind of guidance in the early stage of enrollment, students would subconsciously accept the flipped classroom model. Secondly, in the daily teaching process of World Economy, instructors should further integrate the content of the course to actively guide students to recognize flipped classrooms. Moreover, the explanation and guidance from teachers are more convincing; thus, it is easier for students to accept the teaching model. Finally, in terms of performance assessment, the traditional way is mainly "three sevens"; that is, the average score accounts for $30 \%$ of the total score, and the final score accounts for $70 \%$ of the total score. This is not conducive for students to focus on the learning process. Therefore, in the design of the performance evaluation for the World Economy course, the score ratio can be set as follows: the usual score accounts for $70 \%$ of the total score, and the final score accounts for $30 \%$ of the total score. This would encourage students to pay more attention to the learning process of flipped classrooms to a certain extent, so as to ensure that students would 
be able to learn more in the normal learning process.

\subsection{Equipping with sufficient and high-quality hardware and software equipment}

First of all, it should be fully equipped with free Wi-Fi infrastructure. In the context of flipped classrooms, teachers and students would inevitably use a large number of wireless networks. However, the cost for using wireless network is relatively high, especially during video caching and software downloading. These functions consume a lot of traffic, thereby requiring a high cost. In order to ease the financial pressure on teachers and students, schools should provide full coverage for free wireless networks at teaching areas, thus reducing the economic cost of teachers and students participating in flipped classrooms. This part of the hardware safeguards is what the school must provide. Secondly, it should be adequately equipped with classroom multimedia equipment; that is to say, every classroom that implements the flipped classroom model needs to be equipped with sufficient multimedia equipment, such as computers, projectors, screens, microphones, wired network equipment, and other equipment, so as to ensure the need for hardware equipment would be met. Third, it should be fully equipped with relevant software equipment. In the flipped classroom model, certain software equipment is inevitably needed to cooperate. Although most software are free, whereby teachers and students may download them directly onto their mobile phones or computers, there are still some fee-based software, such as statistical software, econometrics software, video editing software, etc. When encountering a software that needs to be purchased, schools should actively solve it by investing in it, so as to provide an important guarantee for the smooth implementation of flipped classrooms.

\subsection{Scientific evaluation of the teaching effect and timely feedback on flipped classroom}

Since most of the World Economy courses in schools have not completely implemented the flipped classroom model, teachers and administrators need to actively develop scientific teaching methods in the initial stage of implementation. The evaluation indicators for teachers and students need to be scientifically refined to accurately reflect the corresponding teaching effects. First of all, students' learning effects can be evaluated based on their classroom participation and discussion performance through an online software. This includes the time and effect from watching videos, their performances while doing exercises, their enthusiasm to participate in group discussions, and the accuracy of their discussion points. The comprehensive evaluation of these standards is bound to reflect the learning situation of students participating in flipped classrooms to a certain extent ${ }^{[8]}$. Secondly, teachers' participation in flipped classrooms can be queried in the software. All the records of their online interactions during flipped classrooms can be retrieved. This can be used as an important indicator for evaluating teachers' participation in flipped classrooms. Moreover, these indicators can also reflect the teaching effect to a certain extent. Finally, the learning effect of students after participating in flipped classrooms can be compared with that without flipped classrooms, including their performance, discussion, learning ability, etc., so as to find out the advantages and disadvantages of flipped classrooms as well as to make improvements to those deficiencies. At the same time, it is necessary to compare the teaching effect of teachers before and after participating in flipped classrooms, find the shortcomings, as well as optimize and improve the teaching ability of teachers to participate in flipped classrooms.

\section{Conclusion}

There are many problems and drawbacks in the teaching process of the traditional World Economy course. In order to improve the efficiency of course teaching and optimize the learning effect of students, the World Economy course must actively implement the flipped classroom model. This model can further enhance the teacher-student interaction in classrooms, optimize students' learning habits, enhance students' learning 
effects, and provide constructive feedbacks on the teaching effect. At the same time, the implementation of the flipped classroom model requires safeguards, such as actively changing the role of teachers, effectively guiding students to actively participate in flipped classrooms, equipped with sufficient and high-quality software and hardware equipment, as well as scientifically evaluating the teaching effects of flipped classrooms.

\section{Acknowledgements}

Many university leaders, teachers, and students have helped in this research and the writing of this article. Thank you for your support.

\section{Funding}

This study was supported by the Heilongjiang Province Educational Science Planning Key Project Research on the Development Path of Cross-border New Commercial Professionals from the Perspective of Professional Clusters (GJB1320264); Heilongjiang Province Higher Education Teaching Reform Project - Construction and Practice of Cross-border New Commercial Professional Clusters in Russia (SJGY20190522); Heilongjiang Province Higher Education Teaching Reform General Project - Research on the Promotion Path of Professional Internationalization under the Objective of Cultivating Innovative Talents (SJGY20200155); Harbin Engineering University Higher Education Research Project - Research on the Promoting Path of the Humanistic Spirit in the Courses of National Defense Industry Colleges under the Guidance of the New Liberal Arts Practice (2019B40); Heilongjiang Province Educational Science Planning Project (SJGY20200529).

\section{Disclosure statement}

The author declares that there is no conflict of interest.

\section{Author contributions}

Chenggang Wang completed the writing and research work of the entire thesis.

\section{References}

[1] Jones TN, 2015, 160 A Comparison of Traditional Versus Flip-Class Teaching Methods on Student Satisfaction and Assessment. Journal of Equine Veterinary Science, 35(5): 451-452.

[2] Rosa, Hu S, 2019, Research on the Flipped Classroom Environment Evaluation Framework and Index System: Taking College English Teaching as an Example. Global Education Outlook, (5): 54-64.

[3] Erdogan E, Akbaba B, 2108, Should We Flip the Social Studies Classrooms? The Opinions of Social Studies Teacher Candidates on Flipped Classroom. Journal of Education \& Learning, 7(1): 116-124.

[4] Gupta A, Garg D, Kumar P, 2018, Analysis of Students' Ratings of Teaching Quality to Understand the Role of Gender and Socio-Economic Diversity in Higher Education. IEEE Transactions on Education, (99): 1-9.

[5] Zeng M, Zhou Q, Cai G, et al., 2105, Research on MOOC-Based Flipped Classroom Teaching Mode. China Audio-Visual Education, (04): 108-114.

[6] Yang C, 2016, A Review of Research on Flipped Classrooms in Higher Education. Jiangsu Higher Education, 185(01): 65-69. 
[7] Hoole SRH, Sivasuthan S, Karthik VU, et al., 2015, Flip-Teaching Engineering Optimization, Electromagnetic Product Design, and Nondestructive Evaluation in a Semester's Course. Computer Applications in Engineering Education, 23(3): 374-382.

[8] Wang J, 2016, On the Essence of Flipped Classroom. Higher Education Research, 37(8): 53-59. 